\title{
La publicidad y las nuevas narrativas: de la linealidad a la transmedialidad
}

\author{
Marisa Avogadro Thomé \\ (Instituto Universitario de Seguridad Pública, Mendoza - Argentina) \\ Sergio Ricardo Quiroga \\ (Instituto Cultural Argentino de Educación Superior, San Luis - Argentina)
}

Recibido: $27 / 1 / 2016$

Aprobado: 29/02/2016

\begin{abstract}
Resumen. Nuestro entorno se ha modificado. Convivimos a diario en una sociedad real y una virtual, donde las nuevas tecnologías de la información y la comunicación (TIC) ofrecen variadas posibilidades de trasmisión y generación de información, traspasando barreras geográficas y culturales, y recorriendo el mundo en tiempos antes impensados. La revolución digital no ha terminado y como consecuencia el ecosistema mediático no se estabiliza. El aumento de medios y la utilización de las TIC ponen en crisis el sistema tradicional de medios en el contexto de la transformación publicitaria y de posibilidades alternativas de financiación y de negocio. En este sentido, el presente artículo formula un análisis crítico sobre la publicidad y las nuevas narrativas, buscando evidencia bibliográfica adecuada para examinar el camino de la linealidad a la transmedialidad.

Palabras clave: publicidad / nuevas tecnologías / editores / transmedialidad / consumidores
\end{abstract}

\section{Advertising and New Narrative: Linearity to Transmediality}

Summary. Our environment has changed. We live in a real and virtual society, where new Information and Communications Technology (ICT) offers us various possibilities of information generation and transmission, getting through geographical and cultural barriers and crossing the world in record time. The digital revolution is not over and the media ecosystem as a consequence has not stabilized yet. The increasing use of media and ICT has put traditional media in crisis within the transformation of the Advertising industry context and the alternative funding and business practices. Therefore, this article presents a critical analysis on Advertising and the new narratives, trying to find adequate bibliographical support to study the path from linearity to transmediality.

Key words: publicity / new technologies / editors / transmedia / customers 


\section{Introducción}

I nmersos en el ciberespacio, ese espacio sin fronteras que surge de la aplicación de las TIC, navegamos por Internet en un mundo mediado por tecnologías. El espacio de la arroba y las autopistas de la información nos traen nuevas maneras para mirar los acontecimientos, editarlos y leerlos. En este escenario aparecen nuevas narrativas en los materiales periodísticos y publicitarios de los medios de comunicación. Desde la cultura de la virtualidad, colores, imágenes, videos, carteles, flash, entre otros, nos muestran productos y servicios y nos ofrecen sus bondades.

\section{Cultura y cosmopolitismo}

Las tecnologías digitales tienden a transformar la narrativa lineal -caracterizada por ser monológica y lineal-en una experiencia de múltiples voces, en la que cada uno puede intervenir, participar con textos e imágenes en constante interacción en una cultura que promueve las escrituras y reescrituras.

La imagen misma del hombre está puesta en duda por una constante mutación, tan deseada por algunos y tan temida por otros. Prysthon (2002) ha diferenciado el cosmopolitismo moderno del posmoderno, considerando que en el primero rige la dialéctica centro-periferia y las tensiones entre la tradición y las aspiraciones internacionalistas, enfatizando la idea de la existencia de un centro irradiador que es imitado o impugnado. En el caso posmoderno no existe un centro debido al relativismo cultural y la horizontalidad de intercambios a través del ciberespacio.

Prysthon (2002) destaca que la economía global transforma la cultura y las comunicaciones más que el espacio urbano. Los centros de las ciudades desaparecen, los centros comerciales aumentan y el funcionamiento del cosmopolitismo está dado por el mercado orientado hacia la estandarización y la fetichización de los productos culturales.

En este contexto emergente, Rose (2011) caracteriza un nuevo tipo de narrativa emergente que da cuenta desde muchos medios al mismo tiempo de manera no lineal, para provocar la participación como un arte de la inmersión. Es así que los bienes culturales hoy producidos tienen la incertidumbre y volatilidad de la demanda.

Henry Jenkins (2008) ha llamado 'cultura de convergencia' a aquellos procesos de convergencia mediática que impactan en la información, el contenido y la interacción entre diferentes dispositivos mediáticos. El sujeto asiste a la noticia y busca en otros medios (Internet) más información sobre el tema que la complemente, viviendo -de este modo- una cultura participativa. En este sentido, la actividad de las audiencias toma la iniciativa frente a los medios.

En este nuevo escenario, el rol de los medios en la vida de las audiencias 
ha experimentado una transformación notable en las últimas décadas, debido a la rápida transformación tecnológica y la integración de los medios de comunicación en las prácticas sociales e institucionales. La actividad de las audiencias es relevante, utilizando la diversidad y convergencia de los distintos dispositivos tecnológicos. El nuevo entorno de los medios se involucra en una variedad de contextos, con diferentes propósitos y distintas formas de las audiencias.

\section{El nuevo contexto para la prensa}

En este marco de la era digital, la clave del éxito para los diarios reside en generar empatía, motivar y a la vez interpretar al inmenso público que todos los días se expresa a través de las redes sociales. ¿Pero cómo utilizar las prácticas y herramientas para obtener que esos miles de seguidores pongan like o 'me gusta'? Cada medio de comunicación debe prepararse para innovar y conquistar a su público. Pero no pueden ni quieren invertir en investigaciones de mercado costosas; sin embargo, entienden que las redes sociales constituyen un ecosistema de audiencias dinámico. Más aún en el actual contexto, donde el valor de la marca, la estrategia óptima en cada medio y la sinergia entre los departamentos, emergen como un punto de encuentro e intercambio.

Las redes sociales se han revelado como un marco predilecto para que ciertas empresas patrocinen conteni- dos, así como para impulsar diversos negocios de comercio electrónico, alianzas con productoras, sellos discográficos, teatro, cine y televisión, incluso el auspicio de eventos deportivos y artísticos, y el uso ampliado del streaming video (difusión en continuo, donde el consumidor ve el video mientras lo está bajando). La idea perseguida es llegar a la mayor cantidad de nichos posibles de una manera atractiva, innovadora y con réditos sostenidos en ingresos y fidelidad de los lectores con nuevas narrativas y propuestas creativas.

\section{La publicidad}

Comenzamos con una sencilla definición de publicidad que, en términos de Oscar Billorou (1990), es "una técnica para generar actitudes favorables en torno a un objeto comercial, ya sea un producto o un servicio" (p. 1).

La publicidad, vista como una forma de comunicación que pone en común y en contacto dos polos -el que promete y el que desea saber qué promete-, se debe observar como una variable del mercado donde se ponen en juego diversos factores. Por lo tanto, el hecho publicitario no se da aisladamente sino interactuando, de manera tal que se garantice el objetivo de toda campaña: crear conductas positivas hacia el objetivo que la ocupa en esos momentos.

\section{Algo de historia}

Si bien no se puede precisar con exactitud, la publicidad surgió de las rela- 
ciones humanas al aparecer el trueque comercial que tuvo que encontrar algún medio para difundir la información. El desarrollo publicitario creció paralelamente al del comercio.

Uno de los testimonios de la historia publicitaria es una tablilla babilónica de arcilla que contenía una inscripción sobre ganado y alimentos en venta. Herodoto aludía a que en Libia se exhibían mercancías mediante artificios adecuados, en un anticipo del actual escaparate.

En el British Museum se conserva también un papiro egipcio con la noticia de la fuga de un esclavo y el ofrecimiento de una recompensa, que es considerado por muchos especialistas como el primer anuncio. Además, estos pueblos emplearon enseñas para simbolizar las actividades comerciales, tales como una cabra para las lecherías. En Grecia y Roma sucedieron hechos similares. La muestra de una charcutería de Pompeya consistía en el dibujo de unos jamones. En esta ciudad y en Herculano se han descubierto signos pintados en los muros de las casas, de indudable carácter publicitario.

Durante la Edad Media proliferó la forma más elemental de la publicidad, los pregoneros en villas y ciudades de Europa, quienes con su voz proclamaban las excelencias de productos y servicios. Junto a esta actividad surge la exposición, como el interés del mercader para dar a conocer al público las características físicas de las diversas mercancías.
La publicidad ha pasado desde sus orígenes, donde mostró las cualidades de un objeto, a los tiempos actuales, donde ofrece un mundo de fantasías que tienta paso a paso, con mensajes que proponen juventud, vitalidad, sofisticación y placer. Desde un universo meramente informativo a uno simbólico. Desde la linealidad del mensaje a la trasmedialidad y multidireccionalidad de la actualidad.

Estamos, pues, ante la publicidad que -como definición- ha cambiado a través del tiempo, exponiendo las dificultades entre la teoría y la práctica publicitaria. Billorou (1990, p. 1) caracteriza parte del devenir publicitario del siguiente modo: (i) publicidad como técnica en camino hacia la sistematización; (ii) incorporación al patrimonio publicitario de nuevos métodos y técnicas que amplían su campo de acción; (iii) confusión entre publicidad y marketing; (iv) enfoques de los problemas desde ópticas diversas.

Atendiendo a estas dificultades expuestas, el autor define a la publicidad de la siguiente manera:

Es la técnica de la comunicación múltiple que utiliza en forma paga medios de difusión para la obtención de objetivos comerciales predeterminados, a través de la formación, cambio o refuerzo de la actitud de las personas sometidas a su acción. (Billorou, 1990, p. 3)

Sobresale en esta definición la idea de comunicación múltiple, que aprovecha todos los medios disponibles en la concreción de los objetivos planteados. 
La publicidad ha sido y es una fuente de ingresos para los medios, mucho más para los medios digitales, que cuentan con otras posibilidades. Un editor debe prestar atención a las posibilidades alternativas de monetización como una de las variables estratégicas a la hora de pensar en una publicación.

\section{El nuevo periodismo}

Estos tiempos de nuevas tecnologías están signados por la palabra cambio. Hablamos de plantearnos que venimos de procesos rodeados de certidumbres y ahora estamos en terrenos inciertos. Todo lo que era ya no es o, cuando menos, cambió. Se diluyeron las barreras geográficas y nos abrimos a un mundo donde las coordenadas de tiempo y espacio son diferentes. Los imaginarios sociales y comunicacionales también lo son.

La incesante revolución digital conduce a una mayor incertidumbre sobre el presente. La realidad exige que las transformaciones sean cada vez más urgentes, por lo que Roitberg y Piccato (2015) destacan que es necesario contar con un plan de innovación disruptivo que reinvente todas las áreas del negocio de los medios, comenzando por la nueva relación con las audiencias fragmentadas y nómades.

La coexistencia de una sociedad real y una virtual es posible gracias a las nuevas tecnologías de la información y la comunicación (TIC) que han revolucionado la transmisión y la generación de la información, rom- piendo las limitaciones geográficas y culturales, y constituyendo -al mismo tiempo- nuevas delimitaciones culturales en el contexto de la globalización. La introducción de las TIC lleva su influencia al mercado laboral, profesional, económico, político, social, educativo, de seguridad, modificando -de este modo- la vida de las personas y también el desempeño de roles en la mayoría de las profesiones.

En este entorno, el ciberespacio, el espacio donde la 'red de redes' se expande, nos da el lugar físico para la presencia de la cultura de la web. Internet se mueve por pares de opuestos, generando, por así decirlo, una cultura de polaridades. Por ejemplo, una característica de Internet es su libertad, ya que todos los que lo desean pueden publicar sus ideas; pero, al mismo tiempo, se diseminan virus informáticos, remedios 'milagrosos' para enfermedades probadamente incurables, se generan ciberdelitos y una larga lista.

Junto con la libertad en la red se da el anonimato, porque no hace falta que las personas firmen lo que escriben o bien pueden hacerlo con datos falsos. Este anonimato, a su vez, va en detrimento de la credibilidad, la confiabilidad de las fuentes de información y la producción de delitos. De este modo, los elementos que caracterizan y constituyen, por una parte, las ventajas de la cibercultura, se transforman también en desventajas.

Internet está formado por grupos que cambian constantemente, agregan- 
do y quitando personas, conformando -así- un universo multicultural sin fronteras de tiempo y espacio, interactivo y con un sentido de ubicuidad (está en todas partes al mismo tiempo). Internet no solo es una herramienta telemática (conjunto de técnicas y servicios que combinan las telecomunicaciones y la informática) sino un verdadero medio de comunicación. Se perfila una nueva cultura: la cibercultura dentro de la sociedad virtual.

En el camino de la sociedad del conocimiento y de las nuevas tecnologías, se perfilan nuevos roles en el periodismo, cuya actividad tiene por objeto la selección, el procesamiento y la trasmisión periódica de informaciones de actualidad, para un público masivo, o bien para determinados segmentos de ese público a través de medios de difusión masiva. Este quehacer profesional se extiende ahora a un nuevo campo de acción: la red de redes.

El periodismo que se lleva a cabo a través de Internet es denominado de varias maneras: periodismo digital, periodismo on-line, online journalism para los norteamericanos y webjornalismo para los brasileños. Este ciberperiodismo es el que llega a todas aquellas personas capaces de conectarse a Internet, desde sus hogares, oficinas, cibercafés, universidades, organizaciones no gubernamentales, empresas, organismos de gobierno, locutorios; y tanto para estudiantes como profesores, amas de casa, empleados, empresarios, personas en general. En palabras de Salaverría (2005), el ciberperiodismo es "la especialidad del periodismo que emplea el ciberespacio para investigar, producir y, sobre todo, difundir contenidos periodísticos" (p. 21).

Siguiendo la línea de estos estudios, frente a una nueva modalidad de narrar los hechos, también hay personas que tienen una nueva mirada para leerlos y responder. Conforme al planteamiento de Andrés Felipe Gallego (2011), las narrativas transmediáticas representan un cambio de paradigma de la forma tradicional de creación de contenidos, que de procesos enfocados en un solo medio se transforman en estructuras convergentes, donde un relato fluye en múltiples plataformas.

Asimismo, nos abrimos a un mundo periodístico que perdió las barreras de tiempo y espacio, y por consiguiente también estas variables han mutado. Es el universo del minuto a minuto, de la actualización constante. Ya no se pagina, publica y edita de la misma manera. Si se compara la cantidad de materiales que entran en una página impresa de un periódico, por ejemplo en la tapa de una versión impresa, unas seis informaciones frente a las más de veinte que ocupan una primera página (home page) de la versión electrónica. A lo que se le suma que mientras una página impresa tiene una sola versión que circula con el diario, la versión electrónica va mutando a lo largo del día, y agregando en un costado las noticias más leídas y comentadas. Poseen foros, consultas, participación directa de los lectores, que son enriquecidas con materiales enviados por los ciudadanos que leen 
el periódico; y videos que -en algunos casos- produce el mismo periódico. Se pueden leer noticias relacionadas con el tema que aparece debajo o al costado de los títulos que se están leyendo.

Todos estos cambios experimentados en un universo de las tecnologías con hiperinformación, multimedialidad, sin barreras de tiempo y espacio, con ubicuidad, con informaciones confiables, pertinentes y seguras, así como con informaciones apócrifas y ciberdelitos. Ese ciberespacio donde -asimismo- se publican y publicarán las publicidades, que también experimentan cambios. Llegan desde la página de inicio de las publicaciones. Algunas son flashes; otras son versiones estáticas; y otras más aparecen en los videos que se incluyen en la página. Son publicidades que otro medio las coloca como adheridas a lo que se busca. El motor de búsqueda, al reconocer la ciudad desde la cual el lector se conecta, hace aparecer la publicidad de esa región.

El periodismo de las tecnologías y las múltiples posibilidades de información y publicidad, con los cambios realizados y que continúan sobreviniendo con rapidez, provocarán la reinvención de sus productos, las prácticas de trabajo y la relación con las audiencias. El futuro promete altas dosis de innovación y aprendizajes.

\section{Una nueva publicidad}

Así como el material periodístico ha abandonado la linealidad del mensaje para expresarse de forma mutidireccional y transmedial, con el material publicitario ha sucedido lo mismo. El nuevo escenario de la comunicación mediada por la tecnología ha mutado el universo publicitario.

Por una parte, en los periódicos en línea se puede encontrar avisos publicitarios ( $a d s$ en inglés) que presentan imágenes estáticas al igual que un aviso publicado en un periódico tradicional en soporte papel y que se disponen como una bandera, en forma de rectángulo. Asimismo, hay avisos con las mismas características del anterior, mas donde las imágenes están en movimiento y van mostrando por partes la información que contiene.

En otros casos, iguales al descrito, una vez que se muestra el mensaje, se puede dar un click y se va al sitio de la empresa donde se brinda, de forma pormenorizada, la explicación de los productos o servicios. Se pueden ver, pues, los distintos modos de presentar y difundir los mensajes, así como las maneras en que los usuarios-consumidores interactúan con los responsables en una actividad participativa.

También se encuentran, por ejemplo en redes sociales como Twitter y Facebook, 'publicidades pagas', que se distinguen entre los materiales que se comparten, bajo la denominación de Twitter Ads (avisos publicitarios de Twitter) y publicidad (en Facebook).

Por otra parte, se deben mencionar los avisos publicitarios grabados como videos de escasa duración que 
aparecen en YouTube, o incluidos dentro de un video de música, donde la persona que reproduce el video puede detenerlo luego de unos segundos de exposición o verlo hasta el final. Además, hay videos que son únicamente de publicidad.

También encontramos, para determinados tipos de productos, lo que se conoce con el nombre de publicidad transmedia o storytelling, donde se realiza una estrategia publicitaria conforme al perfil del producto o servicio que se ofrece y se presenta la propuesta de modo fraccionado, ofreciendo una narración en la que el usuario participa aportando ideas y sugerencias. En cada plataforma donde se difunde tiene la particularidad de mostrar una narración diferente, que si bien mantiene el hilo conductor, presenta particularidades que se integran desde los mensajes que se propalan en los diferentes medios de comunicación en Internet. De ahí el término de transmedia ('trans': a través; media: plural de medio).

En la actualidad, los diarios están pensando en qué modelos de financiación en línea podrán aplicar en los medios digitales. La lucha por sobrevivir en el negocio de los medios digitales adquiere relevancia cuando se piensa en cómo monetizar los contenidos online.

Moreyra (2015) señala que hay tres modelos principales de monetización en la industria de los medios digitales. Ellos son: modelos de pago por usuario, modelos fondeados o subsidiados y modelos híbridos. Los modelos híbridos son aquellos donde se ofrece un producto o servicio de manera gratuita, cobrándose por funcionalidades adicionales. También afirma que el noventa por ciento de los consumidores están influenciados por los comentarios de los otros consumidores en las redes sociales y que la moneda digital representa una enorme oportunidad para la monetización en el futuro.

Roitberg (2015) resalta que tres organizaciones han comenzado a destacar el statu quo del periodismo en lo referido al intercruce de disciplinas y a la experimentación de nuevas y más eficientes formas narrativas: KnightMozilla Open News, The Guardian y la BBC. Dafra (2015) señala que si bien la publicidad es una fuente de ingresos para los medios, existen otras posibilidades alternativas como la publicidad a las empresas mediante anuncios marginales, el freemium o muro de pagos (puro, flexible o mixto), el crowfunding (financiamiento colectivo), la filantropía, los seminarios, jornadas, desarrollo de micrositios con auspiciantes, creación de contenidos para terceros, desarrollo de contenidos de smart TV (televisión inteligente), desarrollo de aplicaciones para terceros, contenido diferenciado para móviles y alianzas con proveedores de Internet. Un amplio abanico de posibilidades aparece a la hora de monetizar los nuevos medios digitales.

La efectividad de los modelos de publicación digital influye en la vida de muchas compañías digitales. La mone- 
tización de las fórmulas publicitarias ha ido en favor de modelos freemium por la oferta de funcionalidades. Por ejemplo, El Confidencial Digital (2014) señala que la editorial Prensa Ibérica -uno de los grupos más importantes del ámbito regional en España- ha apostado a una estrategia de muros de pago, una iniciativa de la prensa digital para cobrar por sus contenidos.

La estrategia del grupo pasa por implantar el modelo freemium, que permite a todos los usuarios tener acceso gratuito a los contenidos, pero solo quienes son suscriptores pueden disfrutar de ciertos beneficios, como el acceso a entrevistas, contenidos mejorados y exclusivas. Freemium es una tendencia en franco ascenso, que está apareciendo como la solución preferida de las aplicaciones móviles. Sin duda, todas las estrategias de monetización -al igual que los contenidos- deben enfocarse en la audiencia. Conocer la audiencia es relevante para las publicaciones digitales.

\section{Finalmente}

Los editores necesitan conformar verdaderos equipos interdisciplinarios, donde sobresalga la exploración por lo nuevo, la creatividad, el esfuerzo constante y las ganas de experimentar. Estos equipos deben tomar el fracaso como paso al camino del éxito. Un mal experimento servirá para no cometer el error nuevamente y puede ser la semilla de una publicación exitosa. Una idea puede ser fantástica, pero su con- creción puede tener limitaciones o no ser empática con las audiencias. Es un tiempo del periodismo disruptivo que plantea dificultades y desafíos para la innovación, y que pone en juego y en debate el bagaje de conocimientos que los periodistas y comunicadores traen de sus facultades.

Es un tiempo de nuevas habilidades y redacciones colectivas interconectadas y móviles, capacitaciones continuas; de equipos y de nuevos modelos de negocios, donde no solo existan periodistas que aprovechen el manantial de las TIC y las redes para afirmar sus posibilidades y plantear nuevos encuentros entre los medios y las audiencias. Estudiar los públicos y sus conductas aparece como una obligación de toda publicación en el universo digital.

De lo expuesto, queda en evidencia que los avisos publicitarios no solo han modificado su narrativa, que de la tradicional linealidad de un periódico impreso ha pasado a la transmedialidad de la red como un componente esencial, sino también que el público al que van dirigidos se ha transformado en un público interactivo, que usa los materiales difundidos por Internet; y que los realizadores de los avisos y los editores también han tenido que cambiar el modo de llegar a su target.

Las nuevas formas de producción y los nuevos estilos de consumo propiciados por la aceleración tecnológica han modificado la profesión periodística, la creación y supervi- 
vencia de los medios, sus narrativas y el negocio publicitario.

Por lo tanto, la publicidad también ha pasado de la narrativa de la linealidad a la de la transmedialidad, y -en este camino- se han abierto paso las plataformas digitales. En este universo en constante movimiento y transformación, los editores buscan nuevas alternativas para sus materiales, tanto periodísticos como publicitarios.

\section{Referencias}

Billorou, O. (1990). Introducción a la publicidad. Buenos Aires: El Ateneo.

Dafra, I. (2015). El periodista como emprendedor. En G. Roitberg y F. Piccato (Comps.), Periodismo disruptivo. Dilemas y estrategias para la innovación, pp. 105-110. Buenos Aires: La Crujía Ediciones.

El Confidencial Digital (29 de octubre de 2014). Prensa Ibérica sí apuesta por los muros de pago. Recuperado de http://www.elconfidencialdigital. com/medios/Prensa-Iberica-apuestamuros-pago_0_2371562848.html

Gallego Aguilar, A. F. (2011). Diseño de narrativas transmediáticas. Guía de referencia para las industrias creativas de países emergentes en el contacto de la cibercultura. Recuperado de http://www.afoxcp. com/dw/Diseno_narrativas_transmediaticas_Gallego_2011.pdf
Jenkins, H. (2008). Convergence culture. La cultura de la convergencia de los medios de comunicación. Barcelona: Paidós.

Moreyra, M. (2015). Tendencias y futuro en la monetización de productos digitales. En G. Roiyberg y F. Piccato (Comps.), Periodismo disruptivo. Dilemas y estrategias para la innovación, pp. 69-77. Buenos Aires. La Crujía Ediciones.

Prysthon, A. (2002). Mercados globalizados e cultura: cosmopolitismo pós-moderno. En Prysthon, A. F., Cosmopolitismos periféricos: ensaios sobre modernidade, pós-modernidade e estudos culturais na América Latina, pp. 93-103. Recife: Bagaço, 2002.

Roitberg, G. (2015). Identikit del \#periodista del futuro. En G. Roiyberg y F. Piccato (Comps.), Periodismo disruptivo. Dilemas y estrategias para la innovación, pp. 95-104. Buenos Aires: La Crujía Ediciones.

Roitberg, G. y Piccato, F. (2015). Introducción. Un plan de juego hacia el 2020. En G. Roiyberg y F. Piccato (Comps.), Periodismo disruptivo. Dilemas y estrategias para la innovación. Buenos Aires: La Crujía Ediciones.

Rose, F. (2011). The art of immersion: how the digital generation is remaking Hollywood, Madison Avenue, and the Way We Tell Stories. Nueva York: W. W. Norton \& Company.

Salaverría, R. (2005). Redacción periodística en Internet. Pamplona, España: Eunsa Editorial. 